\title{
Real-time thermal imaging and quantitative characterization of adsorption-desorption processes in zeolites and silica gels
}

\author{
By B.G.Vainer*, M.S.Melgunov**, A.B.Ayupov** and V.B.Fenelonov**
}

*A.V.Rzhanov Institute of Semiconductor Physics of Siberian Branch of the Russian Academy of Sciences, 13, Lavrentyev av., Novosibirsk, 630090, Russia, BGV@isp.nsc.ru

** G.K.Boreskov Institute of Catalysis of Siberian Branch of the Russian Academy of Sciences,

5, Lavrentyev av., Novosibirsk, 630090, Russia, MAX@catalysis.nsc.ru

\begin{abstract}
FPA-based infrared thermography and mass-spectrometry have been applied simultaneously to investigation of the adsorption-desorption processes on solid adsorbent surfaces in the presence of various vapors. The formation and movement of the adsorption-desorption heat waves have been observed. Simple mathematical model which is compatible with the obtained experimental data is described.
\end{abstract}

\section{Introduction}

The development of modern noncontact methods and techniques makes possible high-resolution visualization and real-time quantitative characterization of temperature fields in systems where both condensed phase and gas flows are involved. Such trend offers a new paradigm in the detailed pattern recognition and modeling of heat and mass transfer in dispersed and porous media. Application of these techniques to scientific investigation of the abovementioned systems enables obtaining a substantial amount of information about physical and chemical characteristics of the dispersed media, including their structures, without any distortion of the system. It is known that the introduction of any contact sensors such as thermocouples, etc. into the fixed adsorbent bed inevitably results in significant distortion of the local structure of layers and fluids. Besides that, noncontact techniques are convenient and high-performance physical instrument. They allow development of more realistic models for heat and mass transfer in the dispersed and porous materials.

One of the most appropriate and promising methods that possibly can make a breakthrough in scientific area in question is FPA-based infrared thermography. At the same time, despite high potential of this method, its practical use in physical chemistry, including catalysis, adsorption and condensation is still very limited. Infrared camera was used in few studies to visualize the catalytic transformations in solid layers of porous catalysts [1]. However, this was carried out with demonstrative purposes rather than quantitative investigation.

It has been theoretically proved [2,3] that extremely high thermal sensitivity of the FPA-based infrared thermography method can be useful for the studies of gas adsorption on solid thin films. By this contribution, we present our experimental results on visualization and quantitative characterization of the thermal processes occurring during the adsorption and desorption of vapors and gases in grains and beds of various solid adsorbents.

\section{Experimentally}

The advantages of direct observation of sorption thermal effects by means of FPA-based infrared thermography are as follows:

1. Detecting and examination of not only the integral heat of adsorption or desorption, but also spatial distribution of temperature are possible.

2. High time resolution (usually starting from hundredths of a second per image) allows the precise studies of adsorption-desorption and co-adsorption-desorption dynamics of heat generation and heat transfer in various macroscopic structures, including fluids, of various chemical origins.

For our experiments devoted to the study of physical and chemical processes of adsorption and desorption of gases in different zeolites and silica gels we created a special complex of research facilities (figure 1). Block diagram of this complex is presented in figure 2. The basic measuring instrument was the FPA-based infrared camera TKVrIFP/SVIT with a cooled InAs-based infrared detector $[4,5]$. Typical technical characteristics of the camera are given in table 1.

Composition of the gas phase was analyzed by means of QMS-200 mass spectrometer (QMS Series Gas Analyzer, Stanford Research Systems). Inlet gas composition was varied by means of a specially designed mass-flow controller that allowed mixing of two gases, one of which was saturated with adsorbate vapors.

Thermo-adsorption characteristics of the adsorbents were studied in the optical quartz cylindrical tubes with wall thickness of $1 \mathrm{~mm}$. The outer diameters of the adsorbers varied in the experiments in the range of 10-25 mm, the height of adsorbent bed was 150-170 mm. As an example, figure 3 shows the adsorber filled with zeolite bed and equipped 
with solenoid pneumatic valves. Such design allows thermal in-situ studies of adsorption-desorption processes in the swing adsorption installation, meant for extract of the oxygen from air.

The experimental setup shown in figures 1 and 2 was operated in the following manner. The carrier gas (helium or argon) was fed into a saturator filled with liquid (ethanol, hexane or water) heated to approximately $50{ }^{\circ} \mathrm{C}$, after which it was cooled down to $15-22{ }^{\circ} \mathrm{C}$ in a reflux condenser. This provided saturation of gas with liquid vapor that correspond to saturation pressure at condenser temperature. Then the saturated gas was mixed with pure carrier gas in various proportions to achieve the desired partial pressure of vapor. Thus prepared mixture was directed to the adsorber and passed through the adsorbent bed. Gas phase analysis was provided at the outlet of the adsorber by means of QMS-200 mass spectrometer.

Accumulation of spatial temperature distribution experimental data was carried out by acquisition and saving the successive thermal patterns with the rate of about $30 \mathrm{fps}$, following which the co-axial temperature profiles in the beds during adsorption-desorption cycles were retrieved from the thermograms and then analyzed. Desorption was performed by switching between flow containing adsorbate vapor and flow of pure inert gas.

\section{Adsorbents}

In this work, we used spherical granules of LiNaLSX zeolite with mean sizes of $0.4 \mathrm{~mm}$ and $1 \mathrm{~mm}$, spherical granules of KSK-2 silica gel with mean size of $3 \mathrm{~mm}, 5-\mathrm{mm}$ shanks of indicator alumina (cobalt nitrate was used as water vapor indicator), and TL-830 (Chemviron Carbon) microporous carbon with mean particle size of $0.5 \mathrm{~mm}$. Appearance of these adsorbents is exhibited in figure 4. Prior to adsorption experiments the adsorbents were treated at $250{ }^{\circ} \mathrm{C}$ for 3 hours in oven.

\section{Experimental results}

With the use of the measurement system exhibited in figure 1, several series of experiments were fulfilled to study ethyl alcohol, hexane, water, and normal air adsorption from flow of dry argon or helium in the beds of granular zeolite, silica gel or coal placed in tubular adsorbers of various diameters with walls transparent in the working spectral range of the used infrared camera $(2.5-3.0 \mu \mathrm{m})$.

One of the most interesting and presentable effects observed in the adsorber was the formation and movement of adsorption-desorption heat waves. An example of such a wave is demonstrated in figure 5 . The thermograms show the dynamics of heating and cooling of silica gel (KSK-2) bed during adsorption and desorption of water vapor dissolved in the flow of helium.

Figure 5 gives an insight into what happens inside the adsorber. Adsorption of water vapor at the beginning of the process causes the heating up, which is observed in a real-time regime (appearing of yellow-red patterns in the thermograms). After a lapse of time, the adsorbent situated within the inlet becomes saturated with adsorbed water, and heat emission stops that is accompanied with cooling down of the saturated adsorbent towards ambient temperature (returning of color to blue). As a result, a heat wave is formed and it starts to move slowly from the inlet to the outlet of the adsorbent bed. The rate of movement depends on flow rate. It is revealed in the experiments conducted simultaneously with infrared thermography measurements that water vapor (and some other gases) is completely retained by adsorbent, because no vapor is detected mass-spectrometrically at the outlet of the bed until the heat wave is reached it.

The bottom row of figure 5 exhibits a cooling effect during desorption. After elimination of water vapor from the flow, the remaining pure helium begins rapidly "washing out" the adsorbed water. The corresponding desorption is accompanied with cooling of the bed (the pattern changes color from blue to dark blue), while desorbed vapor readsorbs at the upper layers causing their heating.

Quantitatively, the described effects are represented in figure 6 where the temperature profiles measured along the bed at the moments corresponding to figure 5 are shown. Figure 7 shows the mass-spectra that correspond to the experiments illustrated in figures 5 and 6 . These mass-spectra prove the assumed physical-chemical model discussed above.

\section{Simulation}

A mathematical model of vapor adsorption in the adsorbent layer, which ascribes the adsorption of impurities from a flow of inert gas (figure 8) was elaborated basing on an analysis of reference literature on vapor and silica equilibrium [6], computer modeling of adsorption refrigeration [7], and assuming the transient behavior of the system during adsorption and desorption at elevated pressures, a review of what is given in [8]. The following assumptions were taken in the model:

1. The concentration of vapor is low enough that one can neglect the change in the total volume of the mixture due to adsorption.

2. The kinetics of adsorption is described in the quasi-equilibrium approximation.

3. When considering the concentration gradient inside adsorbent grain, only the external surface of the granules is taken into account; the bulk of the grains is considered homogeneous (pseudo-homogeneous approximation).

4. The gas flow outside the grains is convective (gas pressure is close to atmospheric one).

5. Dependence of pressure on volume and temperature for all gases is described by the perfect gas equation. 
In the context of above-mentioned assumptions, for the element of volume $A \cdot d z\left(A\left[\mathrm{~m}^{2}\right]\right.$ is a cross-section of a bed, $z[\mathrm{~m}]$ is a coordinate along the bed axis), one can consider mass balance equation as:

$$
\varepsilon \frac{\partial c}{\partial t}=-\varepsilon v \frac{\partial c}{\partial z}-(1-\varepsilon) \rho \frac{\partial q}{\partial t}
$$

where

$\varepsilon$ [dimensionless quantity] is the bed porosity (ratio of void volume between adsorbent grains to the whole volume of adsorbent bed); in our calculations, the value of this parameter was assumed to be equal to 0,38 (random packing value);

$c\left[\mathrm{~kg} / \mathrm{m}^{3}\right]$ is the mass concentration of admixture vapor; the typical value for water vapor under gas pressure of $10^{5} \mathrm{~Pa}$ is about $0,025 \mathrm{~kg} / \mathrm{m}^{3}$;

$t[\mathrm{~s}]$ is the time;

$v\left[\mathrm{~m}^{3} / \mathrm{s}\right]$ is the carrier-gas flow rate (the typical value is $4,17 \times 10^{-6} \mathrm{~m}^{3} / \mathrm{s}$ );

$\rho\left[\mathrm{kg} / \mathrm{m}^{3}\right]$ is the adsorbent apparent density (the typical value is $700-800 \mathrm{~kg} / \mathrm{m}^{3}$ );

$q[\mathrm{~kg} / \mathrm{kg}]$ is the vapor adsorption uptake, $\mathrm{kg}$ of adsorbate $/ \mathrm{kg}$ of adsorbent.

The dependence of $\partial q / \partial t$ is formulated as

$$
\frac{\partial q}{\partial t}=k\left(q^{e q}-q\right)
$$

where $k\left[\mathrm{~s}^{-1}\right]$ is the rate of adsorption:

$$
k=\Omega \frac{D_{s 0} e^{-\frac{E_{a}}{R T}}}{R_{p}^{2}}
$$

where

$\Omega$ [dimensionless quantity] is the empirical parameter that characterizes adsorption kinetics in the framework of linear driving force (LDF) model; it is equal to 15 for water vapor adsorbed on silica gel;

$D_{s 0}\left[\mathrm{~m}^{2} / \mathrm{s}\right]$ is the pre-exponential part of the diffusion coefficient $\left(2,54 \times 10^{-4} \mathrm{~m}^{2} / \mathrm{s}\right)$;

$E_{a}[\mathrm{~J} / \mathrm{mol}]$ is the surface diffusion activation energy $(42 \mathrm{~kJ} / \mathrm{mol}) ;$

$R_{p}[\mathrm{~m}]$ is the grain size, typically $0,001 \mathrm{~m}$;

$T[\mathrm{~K}]$ is the temperature;

$R \quad[\mathrm{~J} /(\mathrm{mol} \times \mathrm{K})]$ is the universal gas constant.

The equilibrium vapor adsorption uptake $q^{e q}[\mathrm{~kg} / \mathrm{kg}]$ was assumed to follow Henry's law:

$$
q^{e q}=K_{0} e^{\frac{M Q_{s t}}{R T}} p^{e q}
$$

where

$K_{0}\left[\mathrm{~Pa}^{-1}\right]$ is the adsorption equilibrium coefficient $\left(2 \times 10^{-12} \mathrm{~Pa}^{-1}\right)$;

$M[\mathrm{~kg} / \mathrm{mol}]$ is the adsorbate molar mass $(0,0180153 \mathrm{~kg} / \mathrm{mol}$ for water);

$Q_{s t}[\mathrm{~kJ} / \mathrm{kg}]$ is the isosteric heat of adsorption; for water-silica adsorption, it is assumed to be equal to $2,51 \times 10^{3}$ $\mathrm{kJ} / \mathrm{kg}$;

$p^{e q}[\mathrm{~Pa}]$ is the saturation pressure (3000 $\mathrm{Pa}$ for water vapor).

The derived system of differential equations for the discussed model was solved after semi-discretization procedure in MATLAB environment by means of common differential equations solver ode15s.

Numerical simulations of concentration and adsorption profiles in the layer for typical parameters of adsorption of water and other adsorbates in porous media agree qualitatively with the patterns observed in physical experiments: for example, the absence of water vapor at the outlet of the adsorbent bed was obtained (figures 9,10 ).

The simulation results and analysis of literature have shown possibility of adsorption dynamics modeling under non-stationary conditions using the derived model.

\section{Conclusion}

It is shown in the present contribution that a new approach to the quantitative studies of physicochemical processes occurring during adsorption and desorption of vapors in zeolites and silica gels, consisting of synchronous recording of data acquired by means of FPA-based infrared thermography and mass spectrometry is highly informative and endowed with great prospects. 


\section{Acknowledgements}

This work was supported by the Russian Foundation for Basic Research, grant No. 11-03-00900-a.

\section{REFERENCES}

[1] Digilov R. M., Sheintuch M. "Imaging of heterogeneously catalyzed reactions by time-resolved IR thermography”. The Chemical Educator, Abstr. vol. 8, pp. 206-210, 2003.

[2] Vainer B. G. "Quantitative characterization of vapour adsorption on solid surfaces and estimation of emissivity of solids using narrow-band short-wave infrared thermography". QIRT Journal, vol. 5, pp. 175-193, 2008.

[3] Vainer B. G. "Focal plane array based infrared thermography in fine physical experiment". J. Phys. D: Appl. Phys., vol. 41, pp. 065102, 2008.

[4] Kurishev G. L., Kovchavtzev A. P., Vainer B. G., Guzev A. A., Bazovkin V. M, Stroganov A. S., Subbotin I. M., Zakharov I. M., Efimov V. M., Postnikov K. O., Lee I. I., Valisheva N. A., Panova Z. V. "Medical infrared imaging system based on a $128 \times 128$ focal plane array for $2.8-3.05 \mu \mathrm{m}$ spectral range". Optoelectronics, Instrumentation and Data Processing (Autometria), no. 4, pp. 5-10, 1998.

[5] Vainer B. G. "Narrow spectral range infrared thermography in the vicinity of $3 \mu \mathrm{m}$ operating wavelength". In: Quantitative InfraRed Thermography 5, Eurotherm Seminar 64, QIRT'2000, Reims, France, July 18-21, 2000. Proceedings. Ed. by D.Balageas, J.-L.Beaudoin, G.Busse, and G.M.Carlomagno. UTAP URCA, 2000, pp. 8491.

[6] Ng K. C., Chua H. T., Chung C. Y., Loke C. H., Kashiwagi T., Akisawa A., Saha B. B. "Experimental investigation of the silica gel-water adsorption isotherm characteristics". Appl. Therm. Eng., vol. 21, no. 16., pp. 16311642, 2001.

[7] Wang X., Chua H. T. "Two bed silica gelewater adsorption chillers: An effectual lumped parameter model". Int. J. Refrig., vol. 30, pp. 1417-1426, 2007.

[8] Ruthven D. M., Farooq S., Knaebel K. S. Pressure swing adsorption. VCH Pubslishers Inc., 1994. - 353 pp.

Table 1. Typical technical characteristics of the TKVr-IFP/SVIT infrared camera

\begin{tabular}{|l|l|}
\hline Focal plane array (FPA) format & $128 \times 128$ pixel \\
\hline Typical measurement time & $0,02 \mathrm{~s}$ \\
\hline Maximal frame frequency & $100 \mathrm{~Hz}$ \\
\hline $\begin{array}{l}\text { Camera sensitivity (NETD) } \\
\left(\text { at } \mathrm{T}=30^{\circ} \mathrm{C} \text { and frame frequency } \mathrm{f}=25 \mathrm{~Hz}\right)\end{array}$ & $<0.03^{\circ} \mathrm{C}$ \\
\hline Spectral sensitivity & $2,5-3,05 \mu \mathrm{m}$ \\
\hline Target temperature range & $15-41^{\circ} \mathrm{C}$ \\
\hline $\begin{array}{l}\text { Duration of work at one-time filling with } \\
\text { liquid nitrogen (200 ml) }\end{array}$ & $>10 \mathrm{~h}$ \\
\hline Camera power supply & $\begin{array}{l}\text { from USB } 2.0 \\
\text { port }\end{array}$ \\
\hline Camera weight & $<4 \mathrm{kG}$ \\
\hline
\end{tabular}




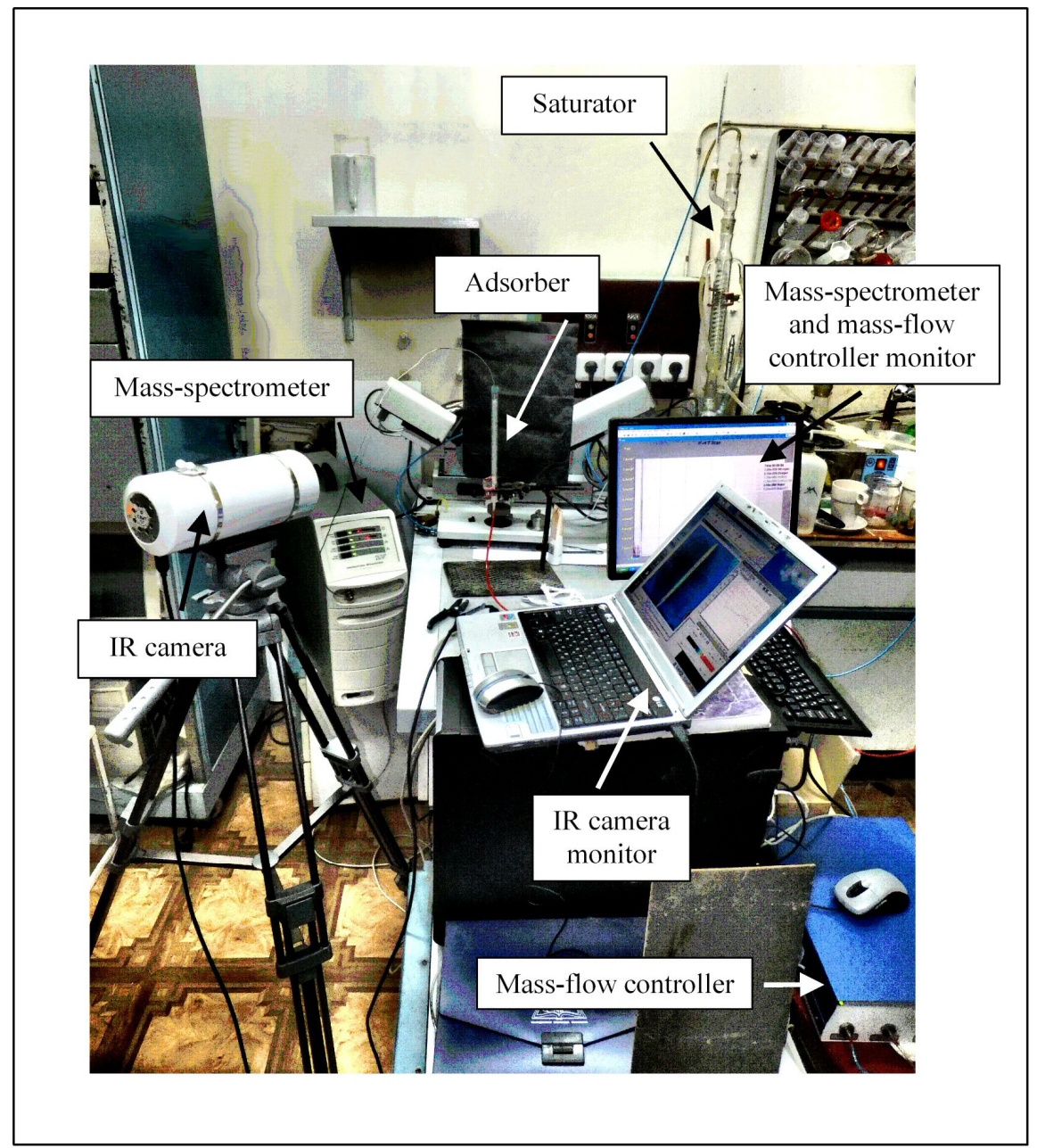

Fig. 1. Major equipment of the experimental setup for infrared thermography-based vapor adsorption-desorption studies.

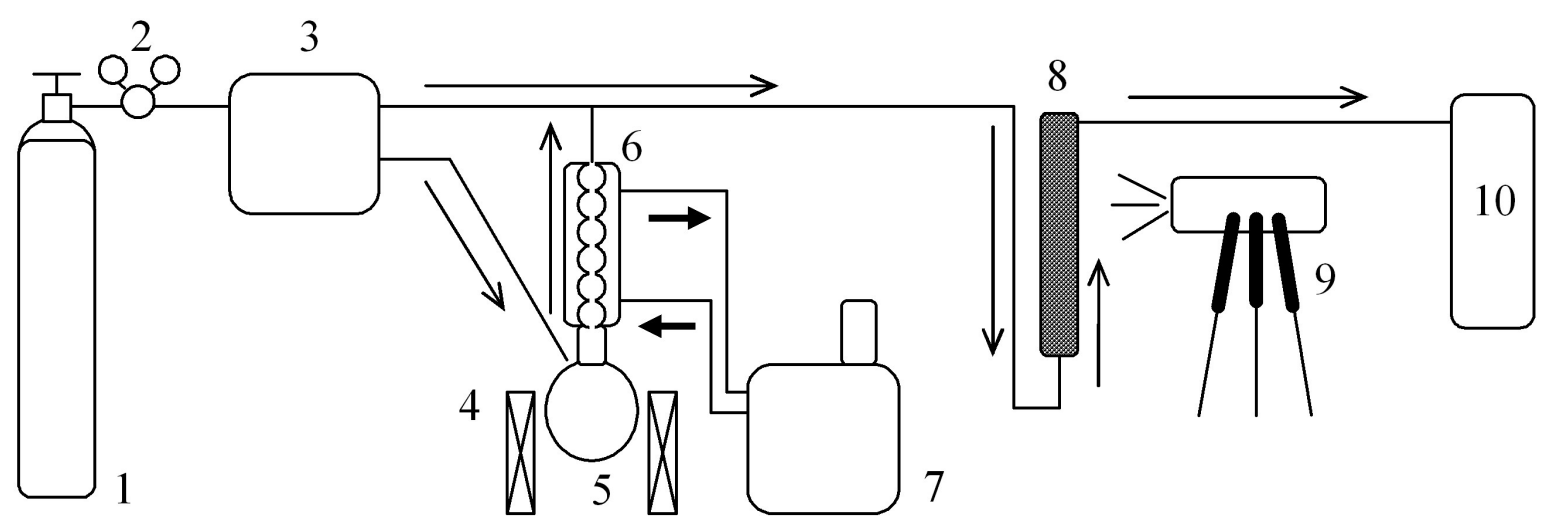

Fig. 2. Block diagram of the experimental setup. 1 - inert gas tank, 2 - pressure regulator, 3 - two-channel mass flow controller, 4 - heater, 5 - vessel with liquid, 6 - reflux condenser, 7 - water thermostat, 8 - adsorber with adsorbent bed, 9 - infrared camera, 10 - mass-spectrometer. Thin long arrows show gas flow direction, thick short arrows show the flow of water from water thermostat to outer jacket of the reflux condenser and back. 


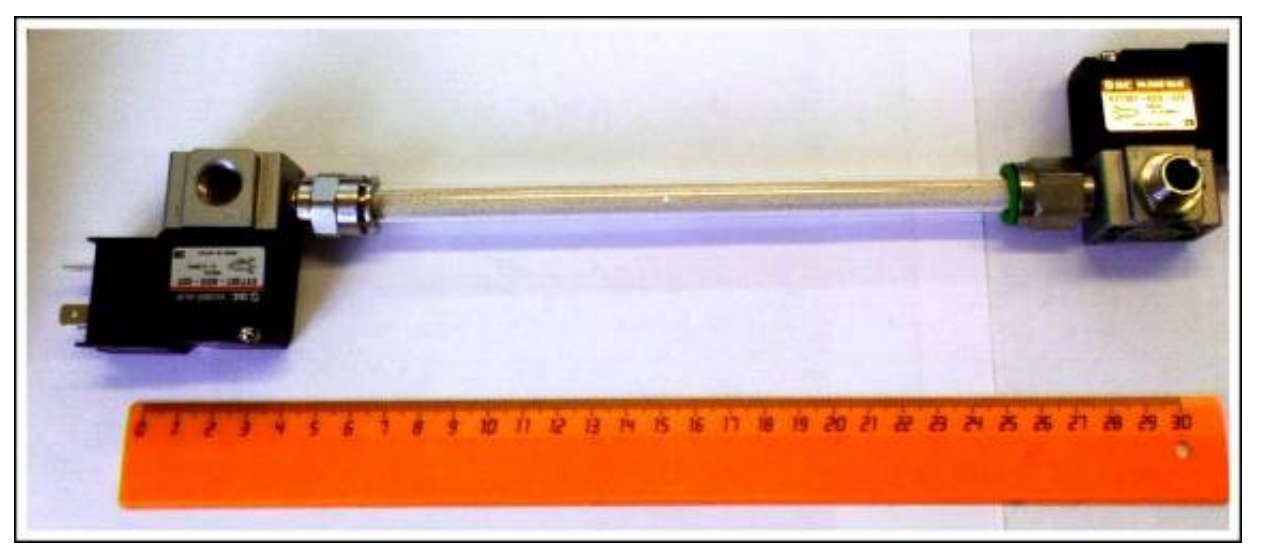

Fig. 3. Adsorber assembly including solenoid pneumatic valves and the tube with adsorbent bed. External diameter of the tube is $10 \mathrm{~mm}$, adsorbent grains size is $0.4 \mathrm{~mm}$.

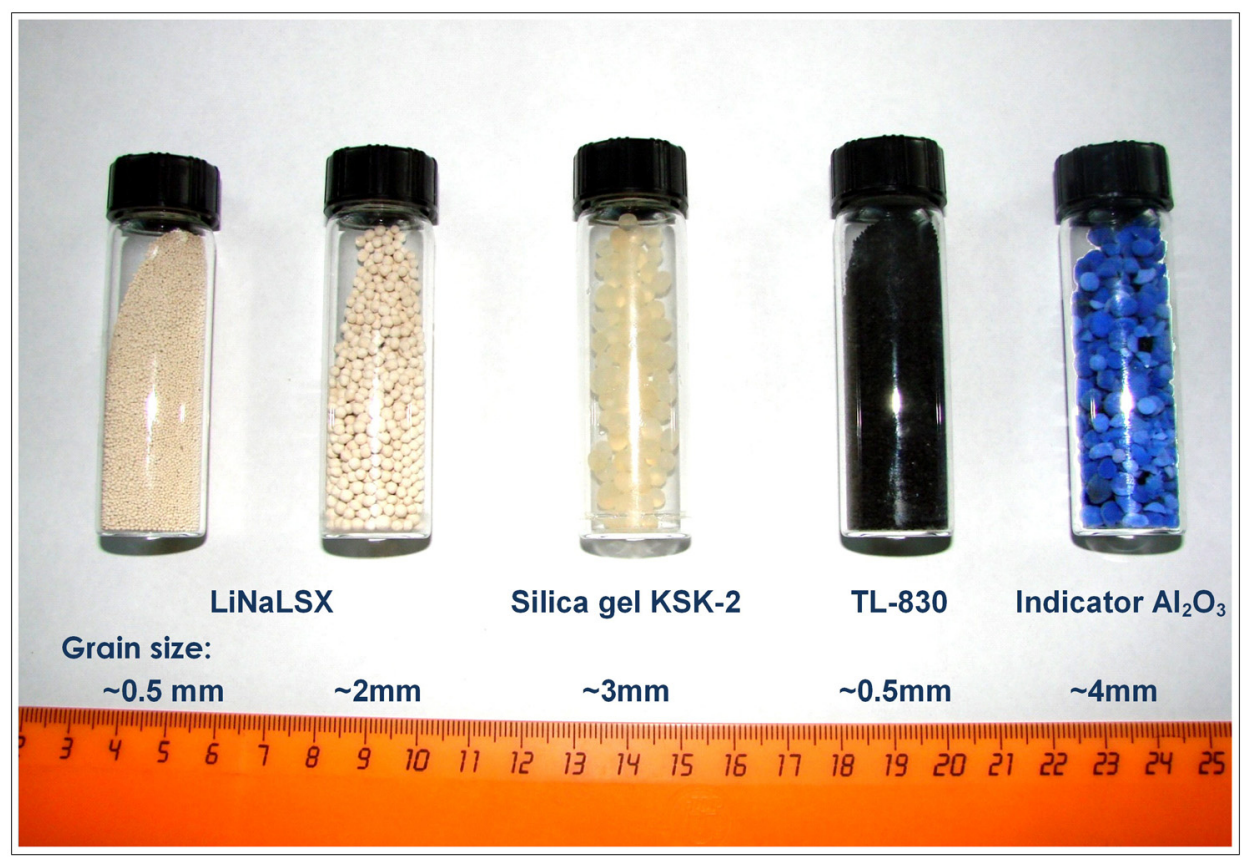

Fig. 4. Appearance of the adsorbents. From left to right: LiNa Low silica $X$ microporous zeolite of two different grain sizes, mesoporous silica gel, activated carbon $\mathrm{TL}-830$, dry $\mathrm{Al}_{2} \mathrm{O}_{3}$ impregnated with cobalt sulfate. 


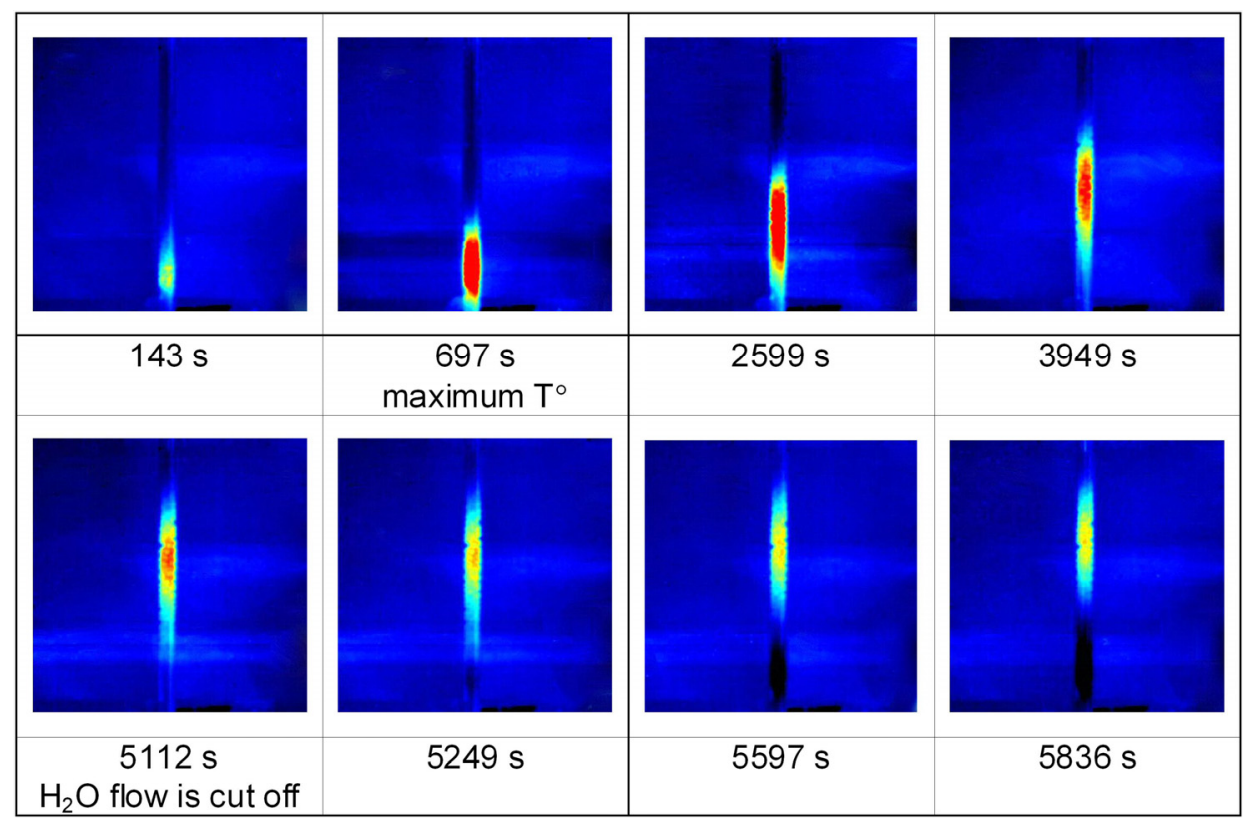

Fig. 5. Top row: the movement of a heat wave in the adsorbent. The process of water vapor adsorption from helium flow in a silica gel bed in a tubular adsorber (reactor) at various moments (indicated under the thermograms) is visualized.

Bottom row: thermal processes in the reactor after elimination of water vapor from the flow.

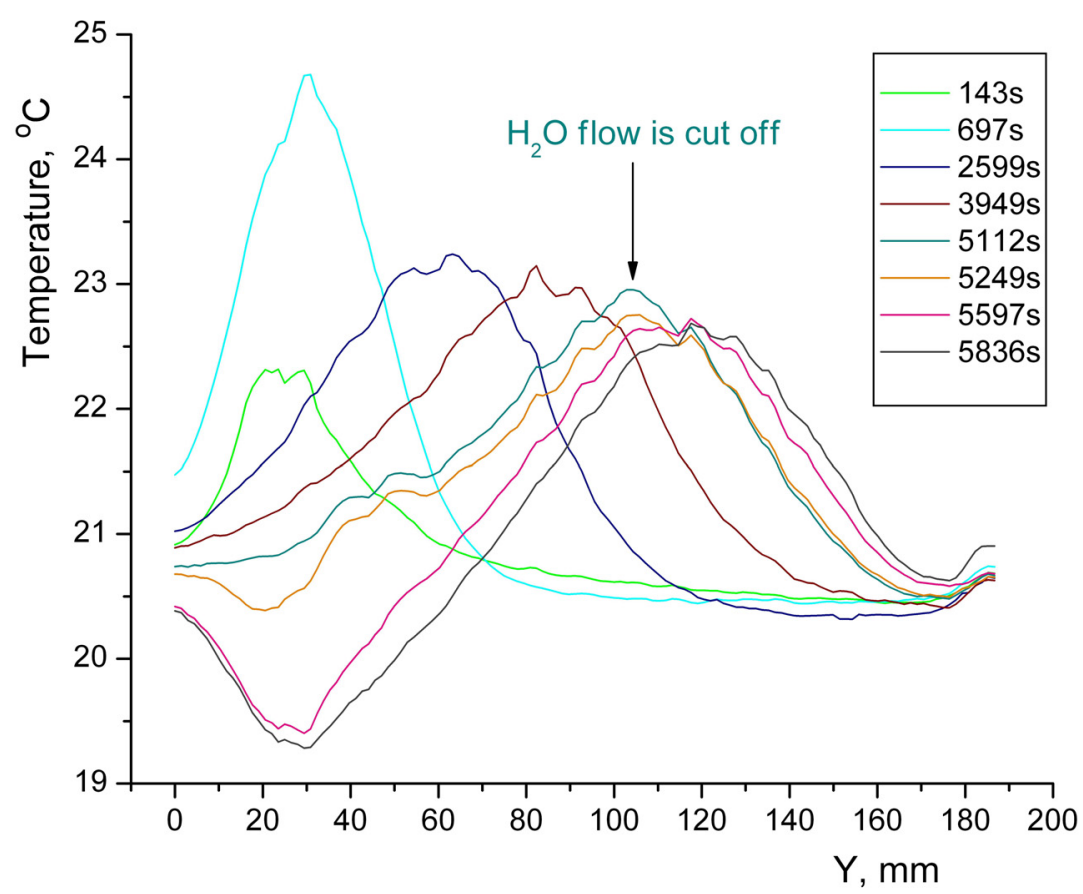

Fig. 6. Temperature profiles measured along the bed of silica gel in the process of adsorption-desorption of water vapor from helium flow. The curves correspond to the thermograms shown in figure 5. Lower parts in the thermograms correspond to the left side on the chart.

Temperature dip emerging after elimination of water vapor is associated with the cooling of silica gel as a result of nonequilibrium desorption. 


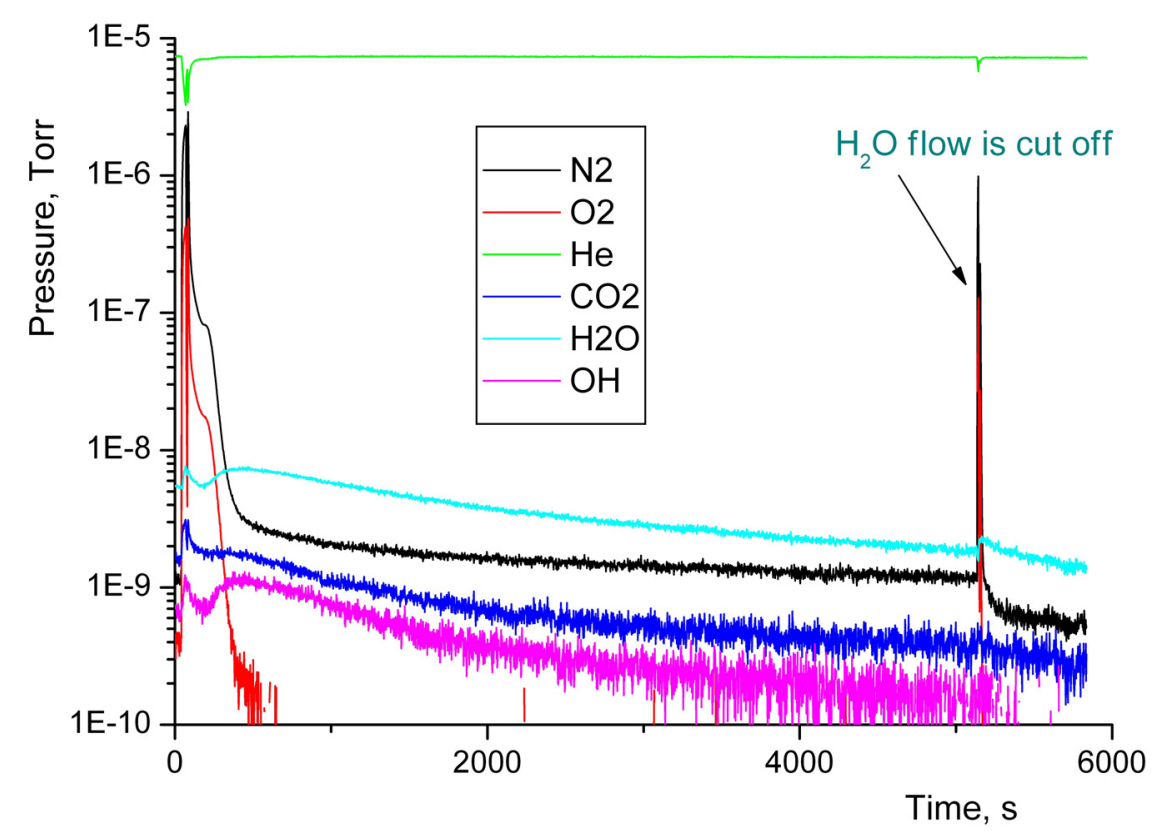

Fig. 7. Mass-spectral profiles as detected in the chamber of a mass-spectrometer. Gas probed from the outlet of adsorbent bed. The spectra were measured simultaneously with thermograms collection (figures 5 and 6). Water vapor (18 ${ }^{\text {th }}$ mass) is absent at the outlet since its only trace quantity is detected.

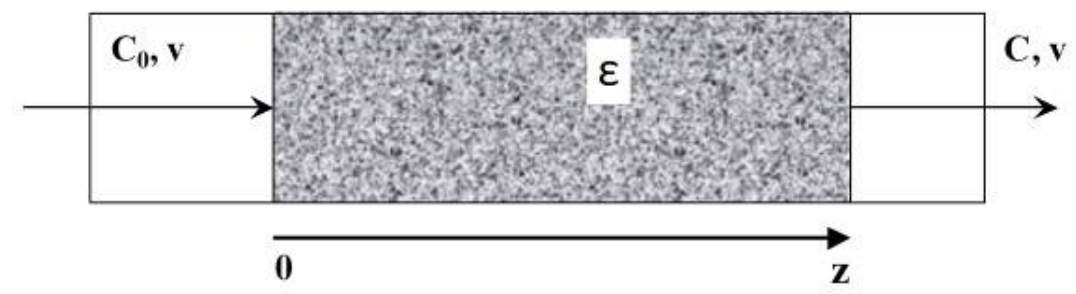

Fig. 8. Scheme of the adsorbent bed model. The direction of a feed gas flow is shown by arrows. 


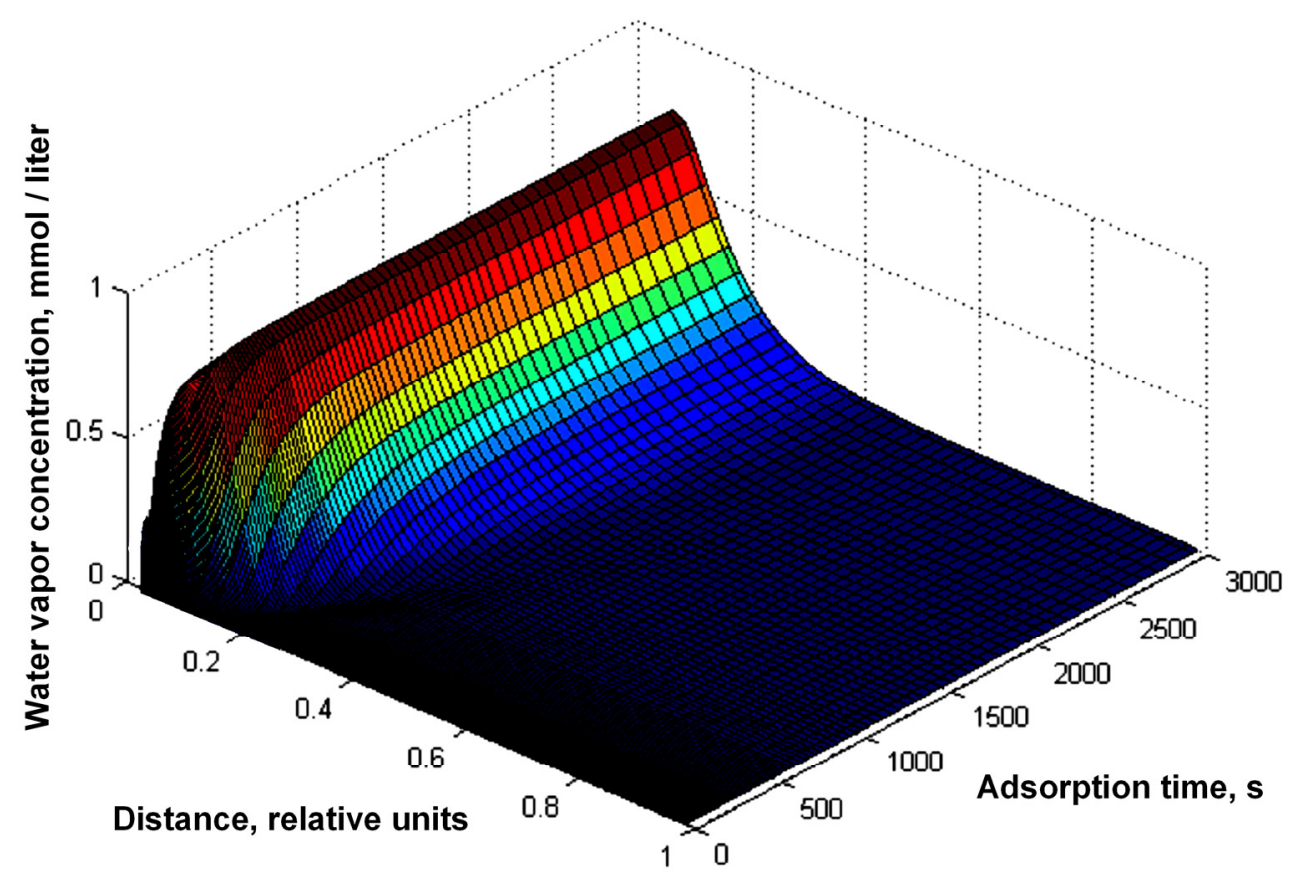

Fig. 9. Simulated co-axial water vapor concentration profiles for isothermal conditions (298 K) calculated for various moments from the model start of adsorbent bed feeding. Water vapor concentration front moves in time along the bed axis.

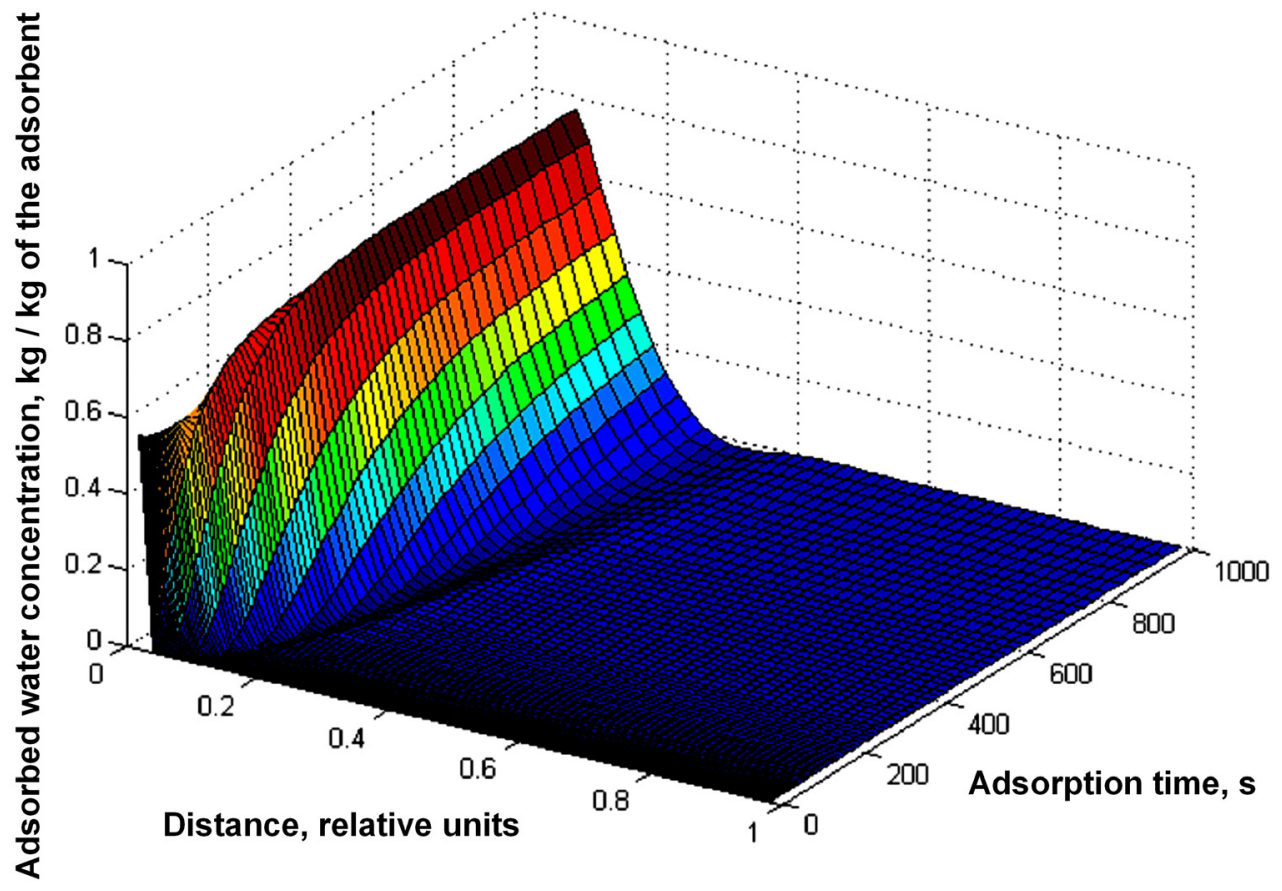

Fig. 10. Simulated adsorbed water profiles under conditions similar to the conditions for figure 9. 